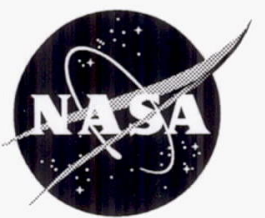

\title{
Investigation of Flow Separation in a Transonic-Fan Linear Cascade Using Visualization Methods
}

Jan Lepicovsky

Dynacs Engineering Company, Inc., Brook Park, Ohio

Rodrick V. Chima, Thomas A. Jett, Timothy J. Bencic, and Kenneth E. Weiland Glenn Research Center, Cleveland, Ohio 
Since its founding, NASA has been dedicated to the advancement of aeronautics and space science. The NASA Scientific and Technical Information (STI) Program Office plays a key part in helping NASA maintain this important role.

The NASA STI Program Office is operated by Langley Research Center, the Lead Center for NASA's scientific and technical information. The NASA STI Program Office provides access to the NASA STI Database, the largest collection of aeronautical and space science STI in the world. The Program Office is also NASA's institutional mechanism for disseminating the results of its research and development activities. These results are published by NASA in the NASA STI Report Series, which includes the following report types:

- TECHNICAL PUBLICATION. Reports of completed research or a major significant phase of research that present the results of NASA programs and include extensive data or theoretical analysis. Includes compilations of significant scientific and technical data and information deemed to be of continuing reference value. NASA's counterpart of peerreviewed formal professional papers but has less stringent limitations on manuscript length and extent of graphic presentations.

- TECHNICAL MEMORANDUM. Scientific and technical findings that are preliminary or of specialized interest, e.g., quick release reports, working papers, and bibliographies that contain minimal annotation. Does not contain extensive analysis.

- $\quad$ CONTRACTOR REPORT. Scientific and technical findings by NASA-sponsored contractors and grantees.
- CONFERENCE PUBLICATION. Collected papers from scientific and technical conferences, symposia, seminars, or other meetings sponsored or cosponsored by NASA.

- SPECIAl PUBLICATION. Scientific, technical, or historical information from NASA programs, projects, and missions, often concerned with subjects having substantial public interest.

- TECHNICAL TRANSLATION. Englishlanguage translations of foreign scientific and technical material pertinent to NASA's mission.

Specialized services that complement the STI Program Office's diverse offerings include creating custom thesauri, building customized data bases, organizing and publishing research results ... even providing videos.

For more information about the NASA STI Program Office, see the following:

- Access the NASA STI Program Home Page at http://www.sti.nasa.gov

- E-mail your question via the Internet to help@sti.nasa.gov

- Fax your question to the NASA Access Help Desk at 301-621-0134

- Telephone the NASA Access Help Desk at 301-621-0390

- Write to:

NASA Access Help Desk

NASA Center for AeroSpace Information 7121 Standard Drive

Hanover, MD 21076 
NASA/TM-2000-210521

\section{Investigation of Flow Separation in a Transonic-Fan Linear Cascade Using Visualization Methods}

Jan Lepicovsky

Dynacs Engineering Company, Inc., Brook Park, Ohio

Rodrick V. Chima, Thomas A. Jett, Timothy J. Bencic, and Kenneth E. Weiland Glenn Research Center, Cleveland, Ohio

Prepared for the 9th International Symposium on Flow Visualization sponsored by the Heriot Watt University Edinburgh, Scotland, United Kingdom, August 22-25, 2000

National Aeronautics and Space Administration

Glenn Research Center 


\section{Acknowledgments}

The authors would like to acknowledge many useful discussions with Dr. E.R. McFarland and Mr. J.R. Wood and engineering support provided by Mr. R. Torres of NASA Glenn Research Center. This program was supported by NASA Glenn Research Center under the Smart Green Engine program managed by Mr. R.D. Corrigan.

Available from

NASA Center for Aerospace Information

7121 Standard Drive

Hanover, MD 21076

Price Code: A03
National Technical Information Service 5285 Port Royal Road Springfield, VA 22100

Price Code: A03

Available electronically at http://gltrs.grc.nasa.gov/GLTRS 


\title{
INVESTIGATION OF FLOW SEPARATION IN A TRANSONIC-FAN LINEAR CASCADE USING VISUALIZATION METHODS
}

\author{
J. Lepicovsky \\ Dynacs Engineering Company, Inc. \\ Brook Park, Ohio 44142 \\ R.V. Chima, T.A. Jett, T.J. Bencic, and K.E. Weiland \\ National Aeronautics and Space Administration \\ Glenn Research Center \\ Cleveland, Ohio 44135
}

\begin{abstract}
An extensive study into the nature of the separated flows on the suction side of modern transonic fan airfoils at high incidence is described in the paper. Suction surface flow separation is an important flow characteristic that may significantly contribute to stall flutter in transonic fans. Flutter in axial turbomachines is a highly undesirable and dangerous self-excited mode of blade oscillations that can result in high cycle fatigue blade failure. The study basically focused on two visualization techniques: surface flow visualization using dye oils, and schlieren (and shadowgraph) flow visualization. The following key observations were made during the study. For subsonic inlet flow, the flow on the suction side of the blade is separated over a large portion of the blade, and the separated area increases with increasing inlet Mach number. For the supersonic inlet flow condition, the flow is attached from the leading edge up to the point where a bow shock from the upper neighboring blade hits the blade surface. Low cascade solidity, for the subsonic inlet flow, results in an increased area of separated flow. For supersonic flow conditions, a low solidity results in an improvement in flow over the suction surface. Finally, computational results modeling the transonic cascade flowfield illustrate our ability to simulate these flows numerically.
\end{abstract}

\section{List of symbols}

$\begin{array}{lll}c & {[\mathrm{~mm}]} & \text { blade chord }(89.2 \mathrm{~mm}) \\ h & {[\mathrm{~mm}]} & \text { blade height }(95.9 \mathrm{~mm}) \\ i_{G M} & {[\mathrm{dg}]} & \text { geometric flow incidence angle }(10.0 \mathrm{dg}) \\ M a_{I N} & {[1]} & \text { inlet Mach number } \\ s & {[\mathrm{~mm}]} & \text { blade pitch }(58.4 \mathrm{~mm}) \\ x & {[\mathrm{~mm}]} & \text { axial distance }(\text { cascade }) \\ y & {[\mathrm{~mm}]} & \text { pitchwise distance }(\text { cascade }) \\ \gamma & {[\mathrm{dg}]} & \text { blade stagger angle }(60.0 \mathrm{dg}) \\ \pi_{C S} & {[1]} & \text { cascade pressure ratio } \\ \theta & {[\mathrm{dg}]} & \begin{array}{l}\text { leading edge camber angle }(-9.5 \mathrm{dg}) \\ \varphi\end{array} \\ \text { chordwise distance (airfoil) }\end{array}$

\section{BACKGROUND}

Flutter in axial turbomachines is a highly undesirable and dangerous self-excited mode of blade oscillation. Modern turbine engines employ transonic fan stages with high aspect ratio blades that are prone to flutter and consequently suffer high cycle fatigue. Therefore, it is imperative to understand the origins of flutter for reliable and safe operation of these engines. Flutter can occur in several different operating regimes [1]. High subsonic and transonic torsional stall flutter, which occurs near the fan stall limit line at speeds up to about $80 \%$ of the design speed and with high 
incidence, has been particularly difficult to model with analytical prediction methods. Previous investigations focused on instability of local supersonic regions on the blade suction surface that are terminated with normal shocks $[2,3]$. It was assumed that under certain conditions the shock wave motion can introduce an additional contribution to the fluctuating forces on the airfoil and thus influence the stability of the system. Follow up investigations, however, showed that the shock wave dynamics associated with transonic stall flutter was insufficient to imply instability in the cascade based on the simple shock motion model [4].

The latest view of the transonic stall flutter origin is that the blade oscillations are triggered by high frequency changes in the extent of the partially separated area on the airfoil suction side. This is supported by the fact that for some of the modern tip-section airfoils at large incidence (about $10 \mathrm{dg}$ ), the shock waves do not appear until very high subsonic inlet Mach numbers have been reached (above 0.95). These inflow conditions are actually at the very upper end of the inlet Mach number range where transonic stall flutter is observed and therefore it is unlikely that flutter is caused by oscillating shocks. Modern transonic airfoils, however, exhibit separated flow regions for subsonic inlet conditions with high incidence $[5,6]$. There is a lack of experimental data describing the separated flow characteristics of modern airfoils for transonic fans. The present study has been carried out to fill in this gap.

\section{TECHNICAL APPROACH}

An important unresolved question involving the flow over the suction side of a modern airfoil for transonic fans is the extent of the separated flow region for a subsonic inlet condition with high incidence. Transonic fan airfoils are designed for precompression, and therefore they have a sharp leading edge, a concave suction surface just downstream of the leading edge, and a very low overall camber. The airfoils are prone to flow separation at off-design conditions. It is very difficult to determine the presence and extent of the separated flow zone just from static pressure measurements on the airfoil surface. The separated flow region is at best recognizable through a plateau in the static pressure distribution that can be detected only by comparison with a static pressure distribution for attached flow. The extent of the flow separated zone can be determined reliably either by directly measuring the flow velocity distribution just above the surface in question or by applying one of the surface flow visualization techniques. Direct velocity measurement, however, requires extensive probe traversing and can be quite expensive and time consuming. Two visualization experimental techniques were used to determine flow behavior on the suction side of an airfoil. They included: (1) surface flow visualization using dye oils, and (2) schlieren and shadowgraph flow visualization. Before describing the experimental techniques, the test facility will be introduced.

\subsection{NASA transonic flutter cascade facility}

The NASA transonic flutter cascade facility has already been described in detail in several publications [2 through 6]; only a brief description is given here for completeness. A schematic diagram of the cascade facility is given in Fig. 1. Room air enters the bell mouth (top left), passes through the test section (inserted photograph), and exits through a diffuser (bottom right) into a low pressure exhaust system. The facility operates in a continuous mode. The test section consists of nine blades. The setting angle of the inlet duct is $20.0 \mathrm{dg}$, and the blade-setting angle is $30.0 \mathrm{dg}$; this results in $10.0 \mathrm{dg}$ chordal incidence for the airfoils. The exit channel is set at an angle of 24.0 dg. This configuration assures a nearly identical flow periodicity for six blades in the cascade (from blade B2 to blade B7; counted from left to right). A complete analysis of the cascade steady state flow periodicity is given in references 6 and 7. Airfoil geometry and cascade geometry is given in Fig. 2 [5, 6]. Flow rate through the cascade (inlet Mach number) is controlled by valves located downstream of the exit diffuser. All the experiments described in this paper were carried out for steady state conditions. It should also be stated here that no boundary layer bleed was employed during this study. 


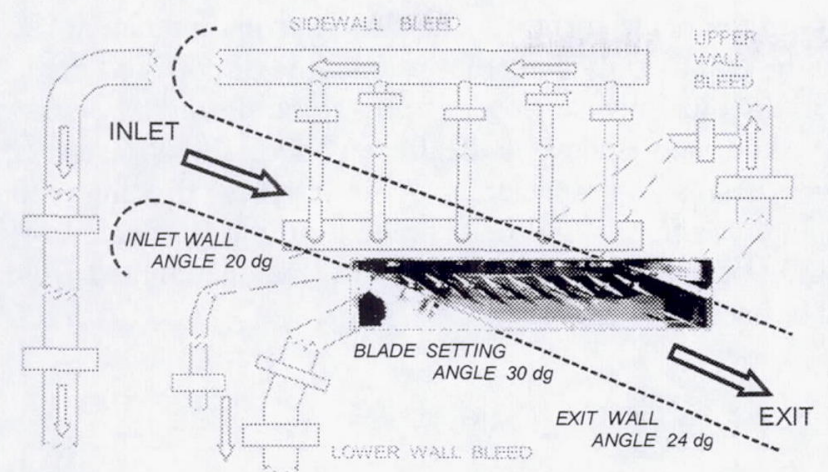

Fig. 1. NASA GRC transonic flutter cascade

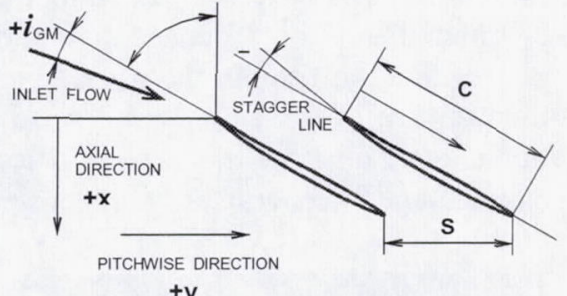

$+y$

Fig. 2. Airfoil and cascade coordinate system

\subsection{Dye-oil surface flow visualization}

Surface flow visualization techniques are based on a dye, which is of a liquid or a solid form, being smeared over the surface by flow. Dye dots or lines are made on the test surface just before the test facility is started. This is relatively simple and straightforward. However, very often, it is difficult to distinguish which of the resulting dye traces were made during the facility start-up process and which were made while running at the test conditions. The shut-down transient is usually no problem because the facility can run until the dye traces are sufficiently dry. To avoid the start-up confusion, some researchers add solid particles in the flow after the test conditions have been established and rely on particle deposition on the test surface [8]. The heaviest depositions are usually along the line of flow reattachment or in the regions of high turbulence intensity. The other approach is to make marks on the test surface with an easily soluble color and then to spray a solvent in the flow at desired operating conditions. Both approaches were tried but without success and therefore an old-fashioned, reliable dye-oil technique was employed.

Using the dye-oil technique, droplets of colored oil are deposited on the test surface and the facility is started. Very often, particularly for low viscosity oils and a slow facility start-up, the recorded flow picture captures the transient flow patterns that occur during the tunnel start-up phase rather than the test flow condition pattern. To avoid this problem, two aspects must be resolved: (1) very short facility start-up time, and (2) a dye-oil mixture of suitable viscosity (in conjunction with small dye-oil marks on the test surface). To minimize the start-up times, the cascade facility operating conditions were set up using the control valves as usual. Then, while the control valves stayed open, the facility was turned on and off using the main shut-off valve only. Through this procedure, the maximum Mach number of 1.2 was reached within $6 \mathrm{~s}$ from the time the main shut-off valve started to open. This extremely short start-up time caused vibrations in the facility and should not be overused; however, so far no detrimental effects on the facility have been noticed. Commercial oil-based paints were mixed with automotive oil viscosity SAE 85W140. The oil/paint mixture ratio was between $3: 2$ and 2:1, depending on the paint color. The right mixture ratio was determined for each color by testing the color mark fluidity. Color dots 2 to 3 $\mathrm{mm}$ in diameter were made on a test surface, and the surface tilted in the vertical direction. Oil was added to the mixture until the color marks started to run after the test surface was tilted.

In preparation for tests, color dots were made on a test blade mounted in the cascade. The blade-setting angle was $30.0 \mathrm{dg}$ with respect to the horizontal direction. For the high solidity cascade, the spacing between the blades is quite small. The dots were made using a 1-mmdiameter copper wire that was dipped in the mixture. The color marks on the cascade sidewall were made on a segment that was removed from the wall as shown in Fig. 3. Behavior of the color dots during the facility start-up procedure was observed to verify that the recorded flow pattern is not contaminated by the transient phenomenon. As mentioned above the flow in the cascade reached the test condition in $6 \mathrm{~s}$. During this period, and for an additional 10 to $15 \mathrm{~s}$, the fluid in the dots was pushed to the downstream side of the dot. Approximately 20 to $25 \mathrm{~s}$ after flow onset the color dots started to break and thin streaks ran over the blade surface. It took about 3 minutes 
for all the fluid from the dot to smear onto the blade surface. The flow was maintained at the test condition for 15 minutes in order to dry the paint. Only one color or one line of dots was made at a time on the blade tested. Each of the multicolor surface flow pictures to be discussed below was completed in 5 or 6 consecutive runs. The consistency of the flow pattern for different colors proves that the flow in the cascade is very stable and repeatable. Also, it proves that the recorded pictures are of the flow at the steady state conditions and that the pattern is not affected by any tunnel start-up flow transients. After the test was completed, the blade was dismounted from the cascade and photographed to record the surface flow pattern.
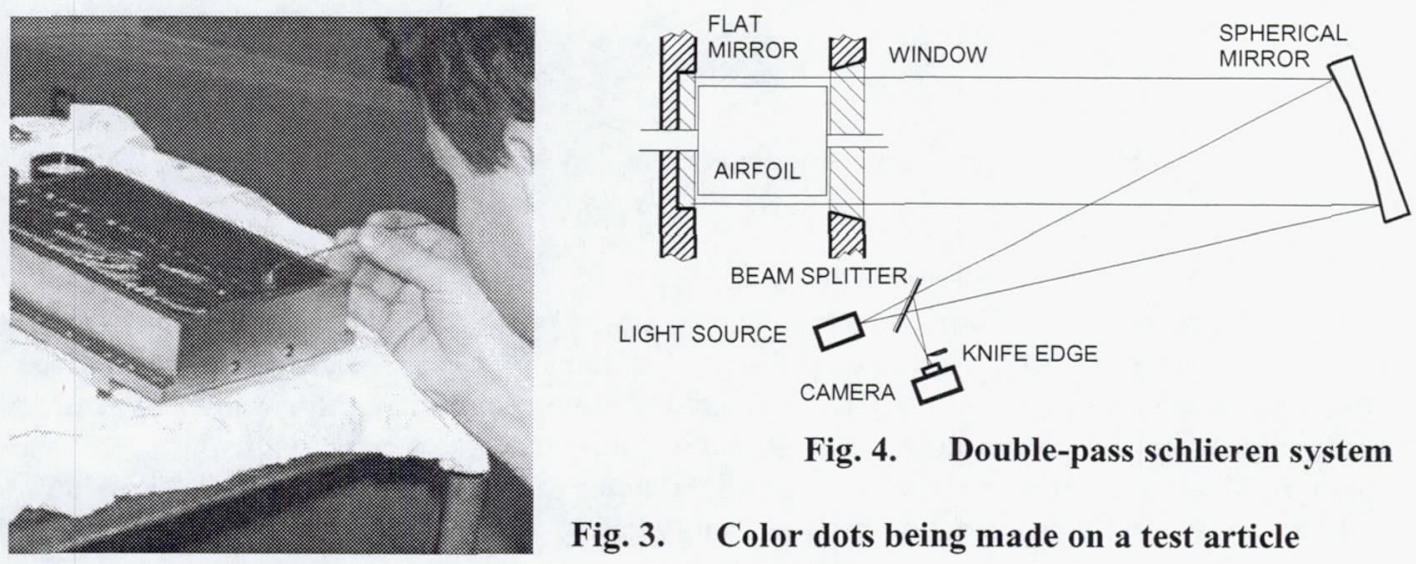

Fig. 4. Double-pass schlieren system

Fig. 3. Color dots being made on a test article

\subsection{Flowfield visualization}

The double-pass schlieren system used in this study is depicted in Fig. 4 [2, 4]. The blades are mounted between end walls with a mirror on one side and optical quality glass window on the other side. The mirror and the window comprise a part of the schlieren system. The limitation in the region of flow visualization over the airfoil surface is due to the large blade trunnion and the blade end fillets. Difficulties were experienced with the alignment of the schlieren system. A perfect alignment of the knife-edge before the test would rapidly deteriorate once the flow started. It is believed that this was caused by minute deflections of the facility walls due to the pressure difference across the tunnel walls. Also, there was a noticeable unsteadiness in the image position at the knife-edge location. For this reason, most of the pictures with shock wave structures present were acquired as shadowgraphs. The flow images were recorded either on a $35-\mathrm{mm}$ camera or a CCD camera with resolution of 512 by 512 pixels.

\section{SURFACE FLOW VISUALIZATION RESULTS}

Solidity is an important parameter in cascade design. It is defined as a ratio of blade chord and pitch. In turbomachinery, high solidity is used to reduce loading and confine the flow, which reduces separation. However, high solidity increases wetted area and losses in a cascade, therefore there is an optimum for solidity of each cascade. The effects of solidity on surface flow pattern are discussed next.

\subsection{High solidity cascade}

The effects of the inlet Mach number on the evolution of the surface flow pattern on the airfoil suction side are shown in Fig. 5. The results are for the high solidity cascade of $\mathrm{c} / \mathrm{s}=1.52$. For subsonic Mach numbers of 0.5 and 0.8 , the flow exhibits a large separated region that starts immediately at the leading edge and extends, at midspan, down to $47 \%$ and $52 \%$ of the blade chord, respectively. A schematic diagram explaining the flow pattern for subsonic conditions is shown in Fig. 6. For inlet flow at the low supersonic Mach number of 1.18 (Fig. 5), the surface flow pattern is completely different. First, starting from the leading edge, the flow is attached to the blade surface down to approximately $32 \%$ of the chord. Then, there is a separated flow region, 

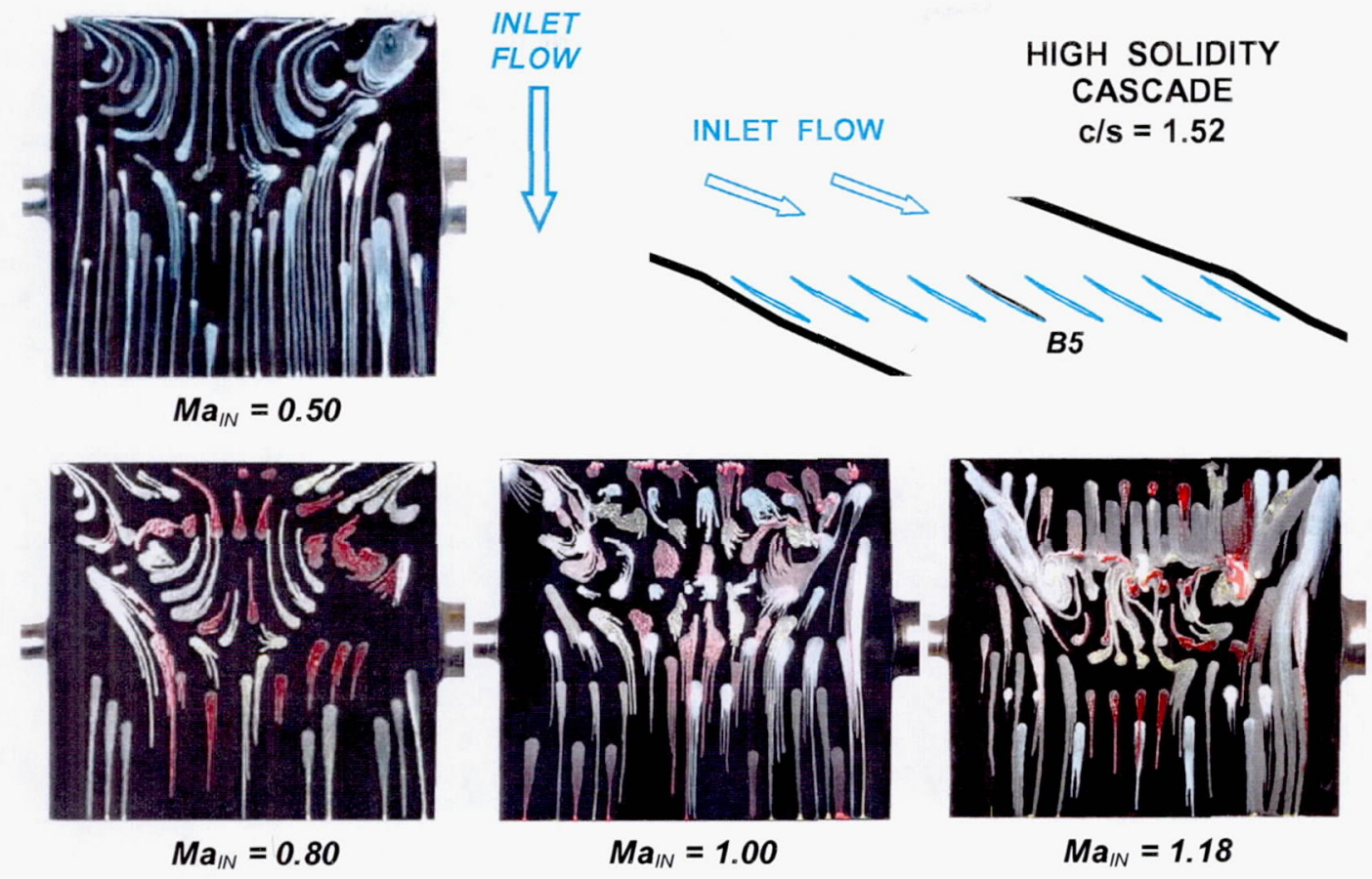

Fig. 5. Effects of inlet Mach number on suction surface flow pattern for high solidity cascade

in which air moves in the direction against the inlet flow. Finally, at a location $62 \%$ of the blade chord, the flow attaches back to the blade surface. The flow behavior can be understood better in Fig. 7, where there is a combination of shadowgraph and surface flow visualization pictures. Starting with the shadowgraph picture, three types of shock waves can be detected here. First, there is a lip (oblique) shock, attached to the blade leading edge. This shock is a consequence of flow overexpansion around the leading edge and adjusts the flow direction along the blade suction surface. As will be shown later, this shock depends solely on the flow conditions at the blade leading edge. The second shock, the bow shock, in particular its location, depends strongly on the inlet Mach number and the cascade solidity. Finally, the trailing edge shock depends on the pressure ratio across the cascade. The oversized blade end fillet blocks the view of the bow shock at the blade suction surface. The projected impact point of the bow shock on the blade surface is indicated by the red-line extension of the shock (the fact that the shock most likely splits into a lambda pattern is ignored here for simplicity). The location of the bow shock impact is redrawn in scale on to the surface flow pattern from the shadowgraph picture. The excellent agreement with the line of flow separation is clearly demonstrated here. The flow separates slightly upstream of the shock due to the secondary boundary layer flow 'under the shock'. The position of the reattachment line (at $62 \%$ of the blade chord) is estimated from the surface flow picture.

\subsubsection{Subsonic inlet Mach numbers}

The effects of cascade solidity on the extent of flow separation were investigated for a high subsonic inlet Mach number of about 0.8. The results are shown in Fig. 8. For the high solidity cascade, the flow on the airfoil suction side is separated at the midspan up to approximately $52 \%$ of the airfoil chord. The separated region is restricted to a parabola, which is symmetric along the blade midspan line and extends to the blade upstream corners. Two swirling traces formed downstream of the blade leading edge corners and rotating in opposite directions are clearly visible here.

The cascade solidity was lowered to 0.76 by removing the even number blades (the cascade was now composed of five airfoils only), and the experiment was repeated. On comparing the results with the previous case, it is obvious that for the lower cascade solidity the separated region is larger and extends down to approximately $65 \%$ chord at the blade midspan. Furthermore, even 


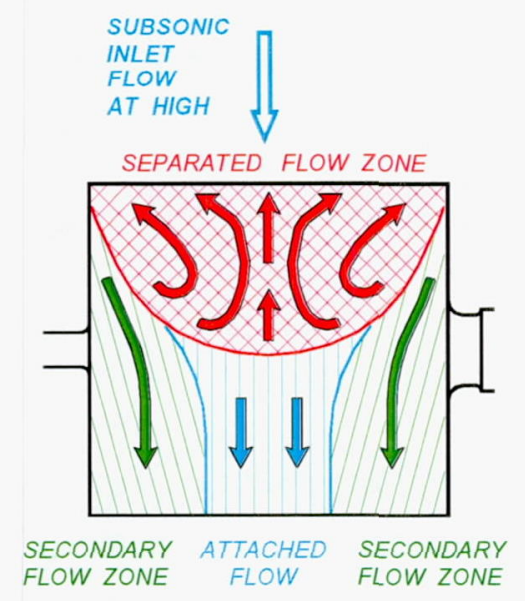

Fig. 6. Surface flow pattern on blade suction side for subsonic flow though the boundary line of the entire separated region seems to be symmetric along the blade midspan line, a closer look reveals that there is an asymmetry in flow traces on the blade. There is an additional swirling pattern in the upper right region that rotates counter clockwise (left of the corner swirling trace that rotates in the clockwise sense). Clearly, there is no symmetry of the flow pattern within the separated flow region.

Finally, the experiment at a high subsonic inlet Mach number was carried out for a single airfoil (blade B5 only). The separated flow region now covers most of the blade suction surface and extends down to the airfoil trailing edge. Only the downstream blade corners show small regions of attached flow. There are again only two counter-rotating swirling traces in the upstream (leading edge) corners, similar to the high solidity cascade case. The boundary of the separated

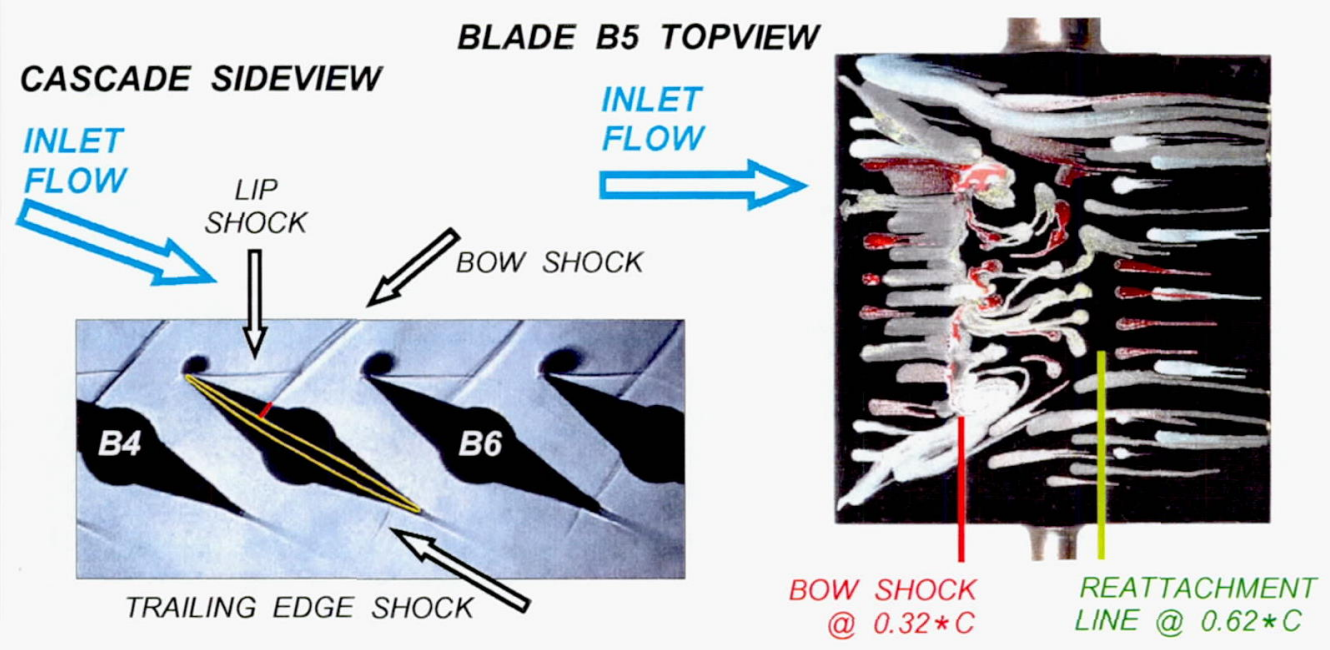

Fig. 7. Surface flow pattern for supersonic inlet flow, $M a_{I N}=1.18$

region, however, is not symmetric along the blade mid span line. The separated flow region is skewed to the left (in the sense of the inflow direction).

\subsubsection{Supersonic inlet Mach numbers}

The results for the supersonic inlet Mach numbers are depicted in Fig. 9. As already indicated in Fig. 5, the surface flow pattern for supersonic inlet flow for the high solidity cascade is dramatically different from the subsonic inlet conditions. The features of the flow pattern for supersonic inlet and the high solidity cascade were discussed in detail in Fig. 7. For the low solidity cascade (see Fig. 9) the flow pattern is essentially similar to the high solidity case with the difference that now the bow shock impinges on the blade surface very close to the trailing edge. The traces of flow separation caused by the shock wave / boundary layer interaction are visible at about $93 \%$ of the blade chord. It should be noted that the shock impingement on the blade is visible only on $18 \%$ of the blade span (in comparison $56 \%$ for the high solidity cascade). The flow is attached on most of the blade suction surface, with secondary flow zones visibly migrating close to the blade midspan line.

The last flow pattern in Fig. 9 is for the case of a single airfoil. Clearly the flow is attached over the entire blade surface. There are no traces of flow separation visible. The secondary flow regions migrate toward the blade center in a similar manner to the two previous cases. While in the 
previous two cases the flow pattern was symmetric along the blade midspan line, for the single airfoil the flow pattern is skewed to the left (in the flow direction), as it was for the case of the subsonic inlet flow.

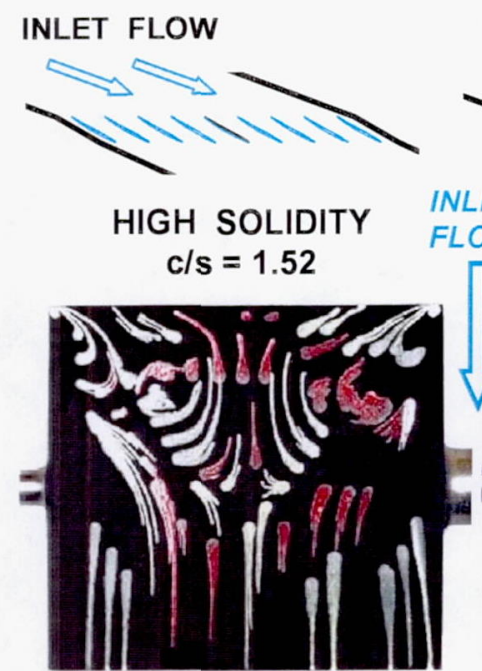

$M a_{I N}=0.80$
INLET FLOW

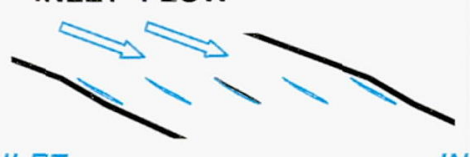

LOW SOLIDITY INLET

$\mathrm{c} / \mathrm{s}=0.76$

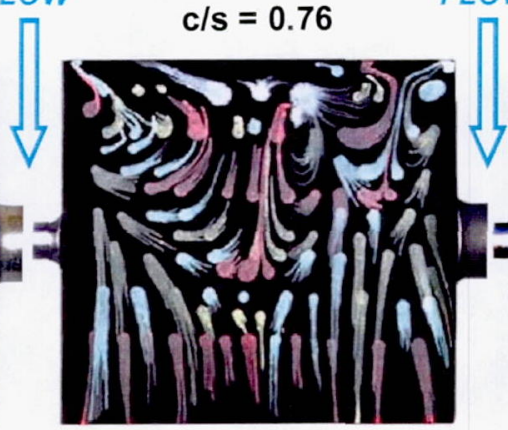

$M a_{I N}=0.81$
INLET FLOW

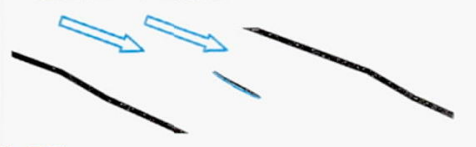

SINGLE AIRFOIL

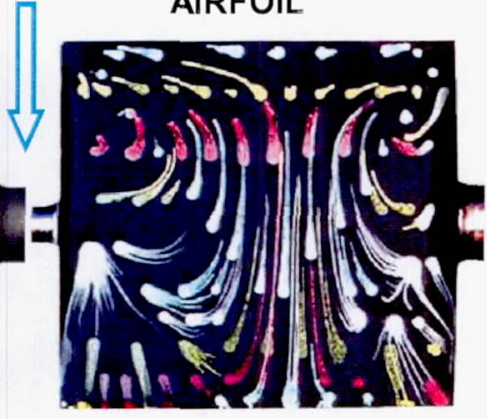

$M a_{1 N}=0.85$

Fig. 8. Effects of cascade solidity for subsonic inlet flow conditions

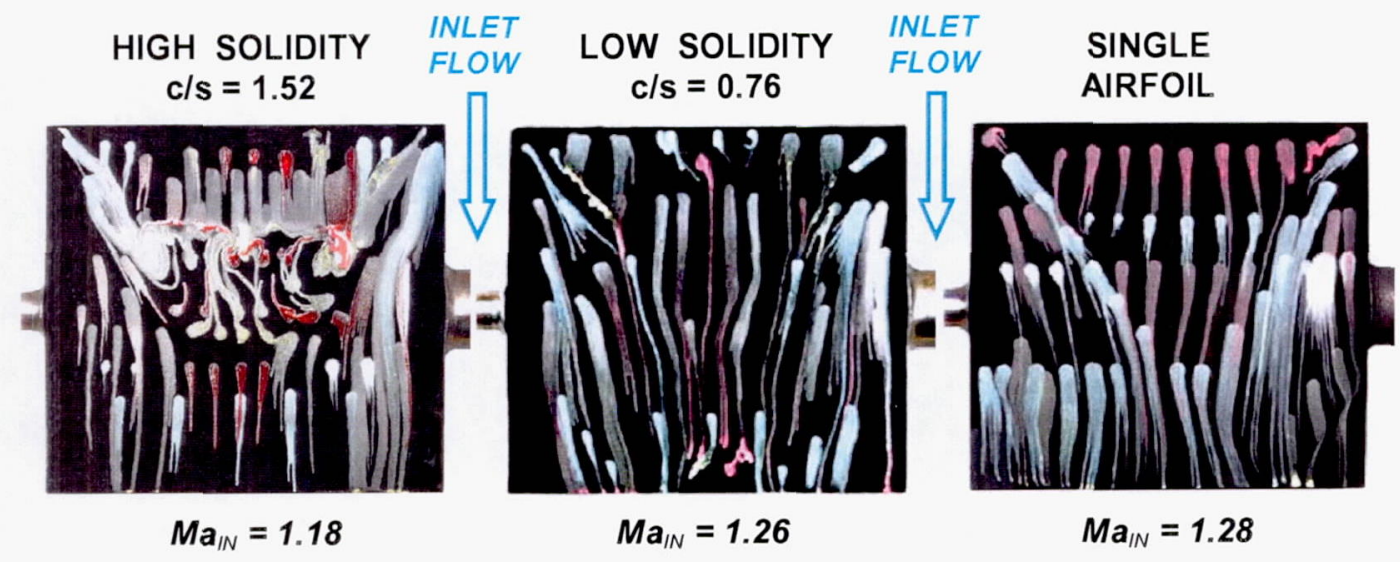

Fig. 9. Effects of cascade solidity for supersonic inlet flow conditions

\section{SHOCK WAVE STRUCTURE}

The goal of the flow visualisation experiment was to determine the onset of shocks in the flow for an increasing inlet flow Mach number and to observe the changes in shock wave structure. The experiments were carried out for a range of inlet Mach numbers starting at 0.6. Three basic configurations were tested: (1) high solidity cascade, $\mathrm{c} / \mathrm{s}=1.52$; (2) low solidity cascade, $\mathrm{c} / \mathrm{s}=0.76$; and (3) a single airfoil.

\subsection{High solidity cascade}

The sequence of photographs in Fig. 10 shows the results for the case of the high solidity cascade. For the subsonic Mach numbers of 0.6 and 0.9 (Fig. 10a,b) there are no shocks present in the flow. Obviously, the critical Mach number for this cascade is above Mach number 0.9. Local regions of high and low pressure in the vicinity of the blade leading edges are visible here (light 
and dark areas). Also, the regions of separated flow on the suction surface, just downstream of the leading edges, can be detected. Wakes downstream of the blades are clearly visible.

The first appearance of shock waves in the flow occurs for the inlet flow Mach number of 1.01 (Fig. 10c). As seen here, the shock structure is not periodic; each blade shows a different
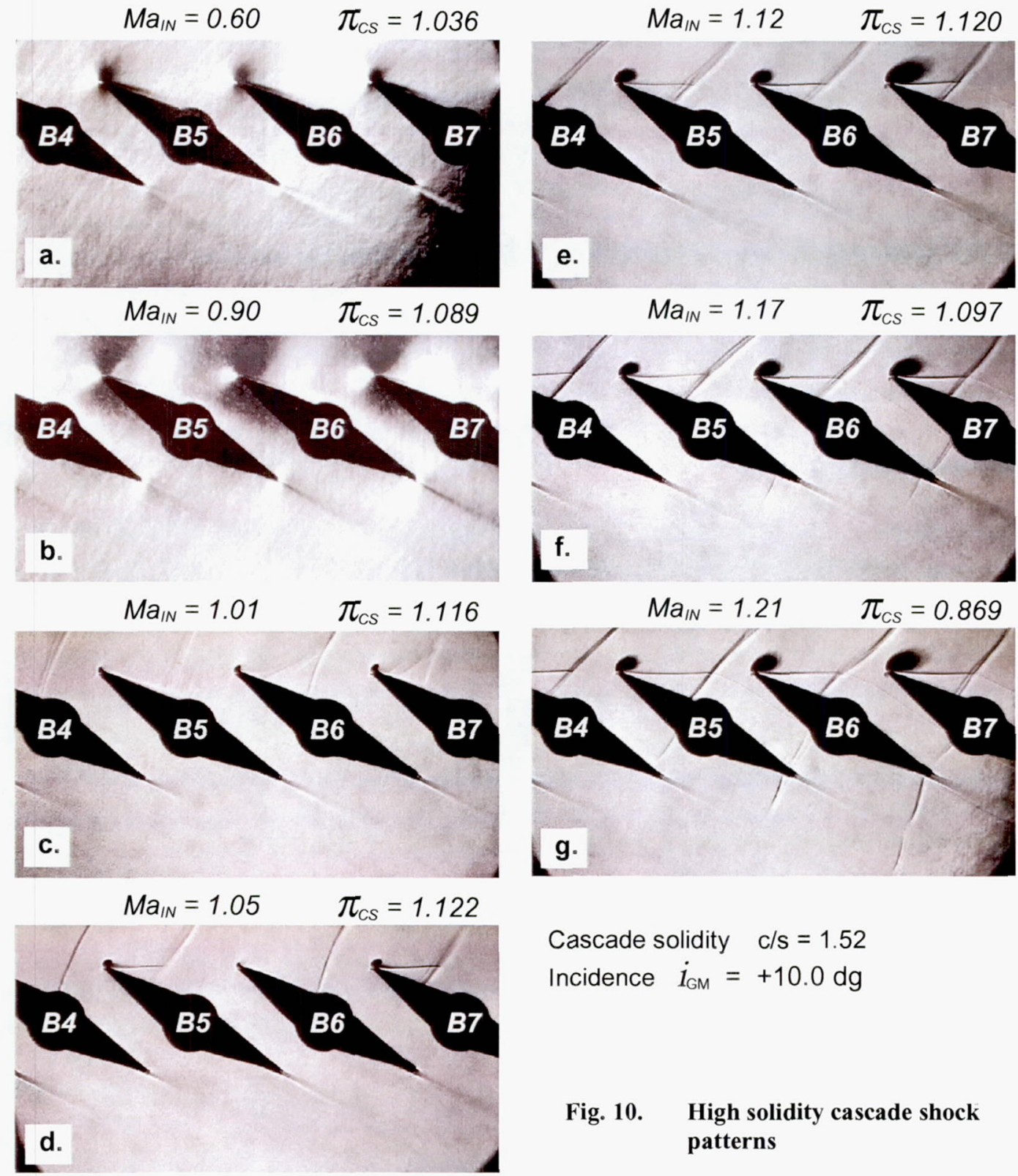

Cascade solidity $\quad \mathrm{c} / \mathrm{s}=1.52$ Incidence $i_{G M}=+10.0 \mathrm{dg}$

Fig. 10. High solidity cascade shock patterns

shock pattern. Blades B4 and B5 generate simple normal shocks, whereas on blades B6 and B7 the shock structure appears to consist of an oblique shock followed by a bow shock. The location of the bow shock, particularly on blades B6 and B7 varies significantly. Direct observation of the shock structure for this inlet Mach number revealed that the shock structure was highly unstable and varied rapidly. Once the inlet Mach number was raised to 1.05 , the shock structure noticeably stabilized and exhibited the pattern shown in Fig. 10d. The shock pattern appears to be periodic with a period equal to two blade pitches. Even blades (B4 and B6) generate normal shocks at $40 \%$ of the blade chord, whereas odd blades (B5 and B7) clearly show a horizontally located oblique (lip) shock attached to the blade leading edge and a normal shock (bow) at $25 \%$ of the blade chord. 
For the inlet Mach numbers of 1.12 and higher (Fig. 10e,f,g) the shock structure is highly periodic with the period of one blade pitch. Additional increase of the inlet Mach number to 1.17 (Fig. 10f) slightly shifts the bow shock in the flow direction. Also, the slip lines separating two subsonic flow streams of different velocity and entropy become clearly visible. Finally, at this operating condition one can observe the formation of trailing edge shocks on blades B5 and B6. At the last test condition (Mach number 1.21, Fig. 10g) the flow in the cascade is choked and the cascade does not generate any pressure increase. The shock wave pattern at the cascade inlet does not change. The shocks in the trailing edge region become more intense and extend more deeply into the flowfield.

\subsection{Low solidity cascade}

The evolution of the shock structure for the low solidity cascade with increasing inlet Mach number (Fig. 11) exhibits some features that are similar to the high solidity case. The shocks appear for the first time in the flow for an inlet Mach number of 0.97 (Fig. 11a). Blade B5 exhibits a bow shock whereas blade B7 still seems to be shock-free. Separated flow is traceable on both blades just downstream of the leading edges. At the inlet Mach number of 1.02 (Fig. 11b), a combination of a lip and a bow shock is generated on blade B5. There is no flow separation at the blade leading edge of blade B5. Blade B7 shows traces of unstable shocks above the suction surface and the flow is visibly still separated at the blade leading edge. A gradual increase of the inlet Mach number (Figs. 11c,d,e) stabilizes the shock pattern in the cascade. Both blades show a combination of lip and bow shocks. On all of these figures, the shock system on blade B7 always appears weaker, as though blade B7 was facing a lower inlet Mach number than blade B5. An interesting shock formation can be detected for the inlet Mach number of 1.19 (Fig. 11f) and higher (Figs. 11g,h). First, a trailing edge shock appears on the pressure side of the airfoil, and with an increasing inlet Mach number this trailing shock penetrates more deeply into the flowfield. Second, and more interestingly, there seems to be an additional oblique shock generated at midchord on the suction side. This shock interacts with the lip shock for inlet Mach numbers of 1.19 and higher. The interaction is manifested by a sudden direction change of the lip shock line.

\subsection{Single airfoil}

The last sequence of pictures presented in Fig. 12 shows the flowfield evolution for a single airfoil. Flow is separated over the airfoil suction side at least up to the inlet Mach number of 0.97 (Fig. 12a). The transition to the lip-shock / bow-shock combination seems to be quite rapid; for the inlet Mach number of 1.04 (Fig. 12b) the combination is already in place. Also, the trailing edge shock waves appear at a lower inlet Mach number than was the case for the low and high solidity cascades; first on the airfoil pressure side at a Mach number of 1.09 (Fig. 12c), and then also on the suction side starting at a Mach number of 1.13 (Fig. 12d,e,f). As the inlet Mach number is raised, the suction side bow shock moves in the downstream direction toward the trailing edge (Fig. 12g). There is a visible interaction of the lip shock with an oblique shock from the blade suction surface starting at the inlet Mach number of 1.20 (Fig. 12f). This is similar to the case of the low solidity cascade as shown in Fig. 11g,h. For the highest inlet Mach numbers (1.26 and higher), the only change in the shock wave structure is a decreasing angle of the trailing edge shock waves as the inlet Mach number is raised.

\section{COMPUTATIONAL RESULTS}

A numerical investigation was also carried out in parallel with the experimental effort. Even though the computational methods and results are not the topic of this paper, the following illustrates some of our capabilities and accomplishments.

Two computational fluid dynamics codes have been used to analyze the blades described here. The first code, RVCQ3D [9] analyzes viscous flow around an isolated blade on a twodimensional blade-to-blade plane. The second code, Swift [10] analyzes fully three-dimensional

blades using a multiblock grid. Both codes solve the Navier-Stokes equations using an explicit finite-difference scheme and an algebraic turbulence model. 

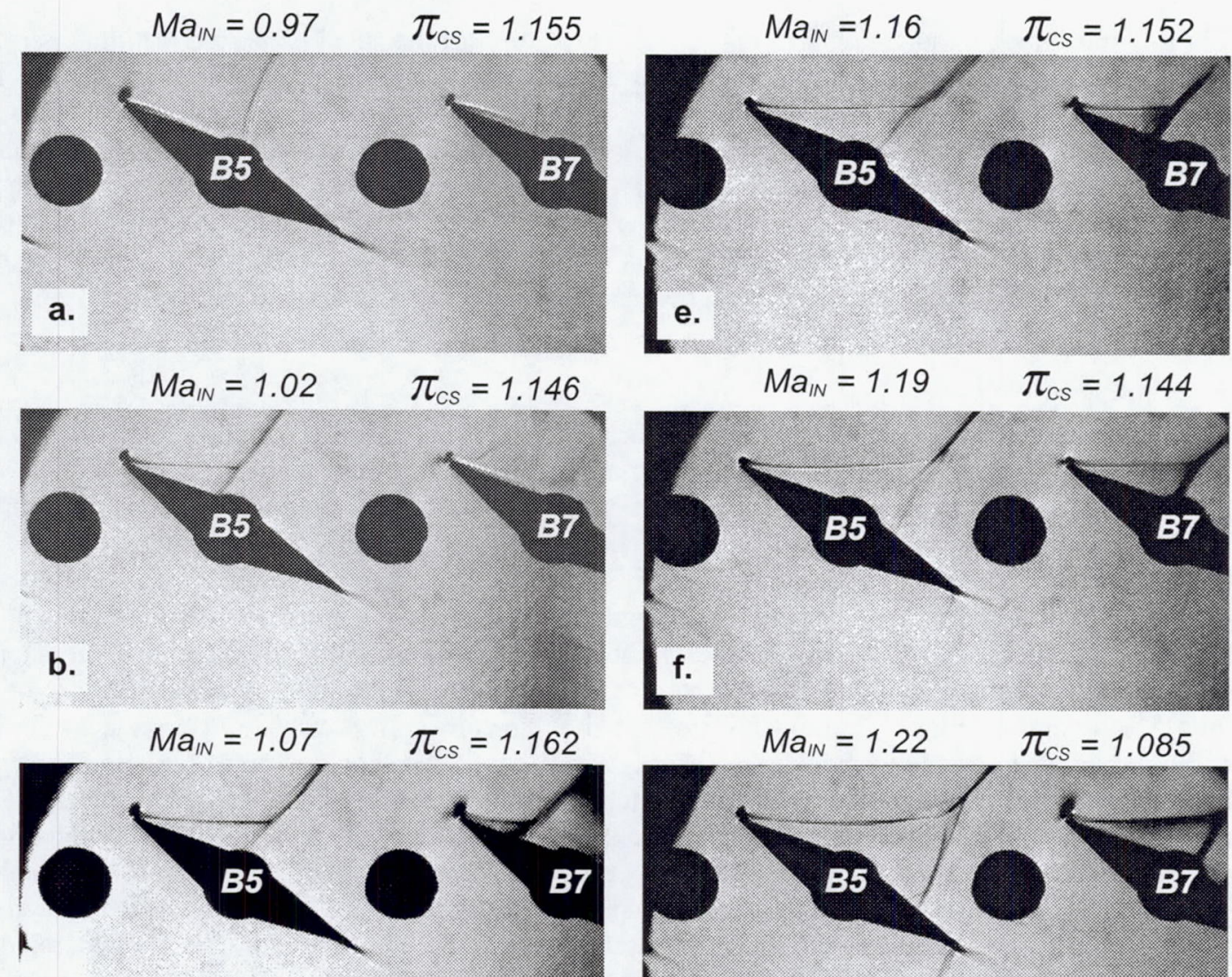

c.
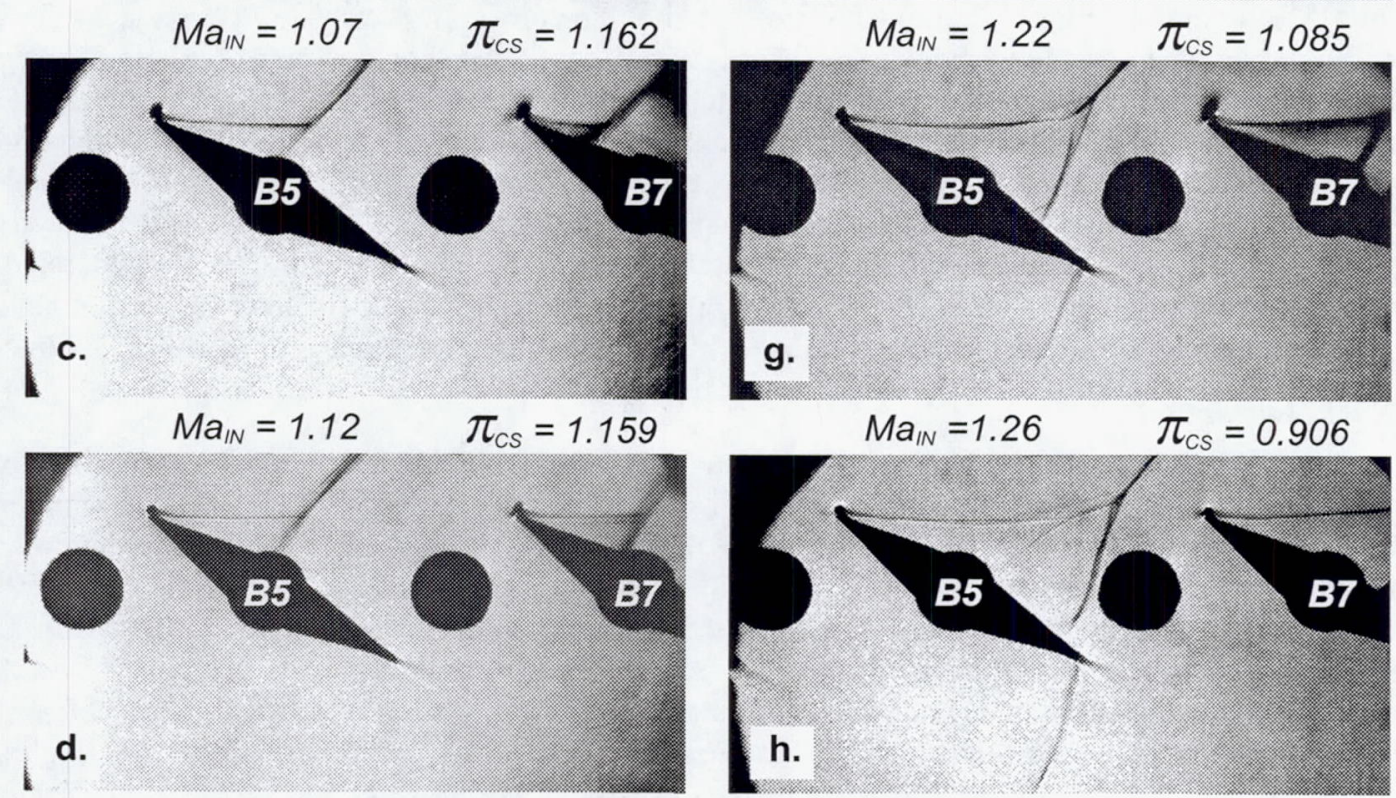

Fig. 11. Low solidity cascade shock patterns

Figure 13 shows a solution computed by RVCQ3D for an inlet Mach number of 1.2 and an incidence angle of $9.0 \mathrm{dg}$. The figure shows contours of the magnitude of the density gradient, which may be compared to the experimental shadowgraph photo shown in Fig. 10g. A strong bow shock wave stands far ahead of the leading edge and hits the neighboring blade normal to the suction surface, separating the boundary layer. A weak lip shock is generated at the leading edge where the blade curvature changes from round to concave on the suction surface. A weak slip line is barely visible where the two shocks intersect at mid passage. Figure 14 shows a solution computed using Swift for a Mach number of 1.10 and an incidence angle of $10.0 \mathrm{dg}$. The figure shows particle traces just above the suction surface, which may be compared to the experimental surface oil flow patterns shown in Fig. $5\left(\mathrm{Ma}_{\mathrm{IN}}=1.18\right)$. The flow is from top to bottom. The supersonic inflow expands around the leading edge and remains attached (red.) The flow separates at the shock (red-blue) and reattaches near mid chord (blue-white.) Secondary flows between the separation bubble and sidewall fillets are also seen (white). 

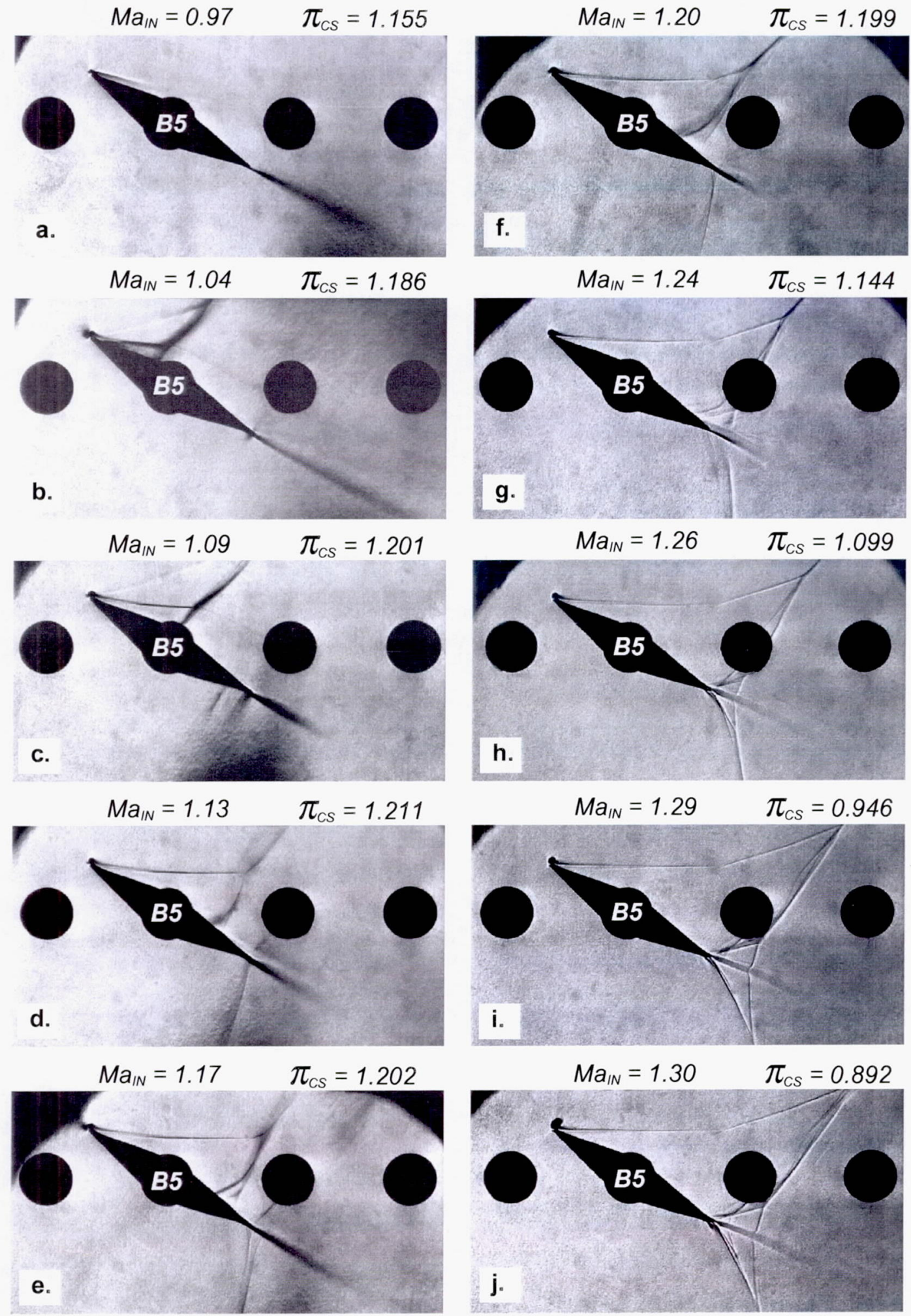

Fig. 12. Single airfoil shock patterns 


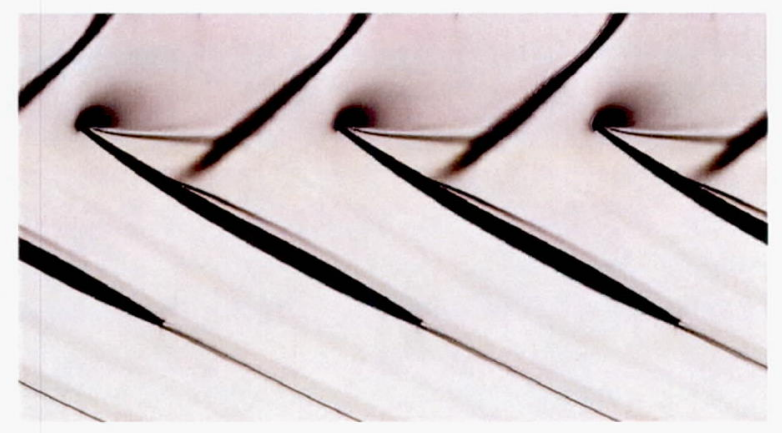

Fig. 13. Computed density gradient pattern for the inlet Mach number of $\mathbf{1 . 2}$ and incidence of $9.0 \mathrm{dg}$

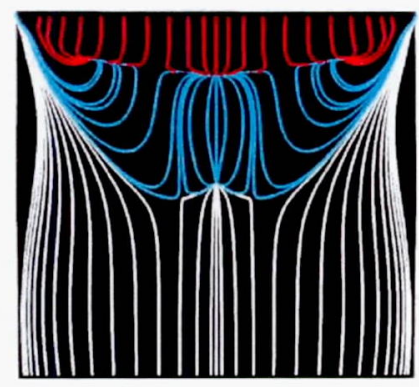

Fig. 14. Computed surface flow pattern for the inlet flow Mach number of 1.1 and incidence of $10.0 \mathrm{dg}$

\section{CONCLUSIONS}

Several key observations were made during the course of this study. They can be summarized as follows.

- For the subsonic inlet flow at the incidence of $10.0 \mathrm{dg}$, the flow on the suction side of the blade is separated over a large portion of the blade surface. The size of the separated area increases with the increasing subsonic inlet Mach number. For the supersonic inlet Mach number the flow is attached from the leading edge up to the point where a bow shock hits the blade surface. The bow shock interaction with the blade boundary layer results in a relatively short separation bubble. For the sonic inlet Mach number, the surface flow pattern on the front half of the suction surface exhibits a high degree of randomness that indicates instability of the local shocks generated in this area.

- The effects of cascade solidity are different for subsonic and supersonic inlet conditions. A low cascade solidity, for the subsonic inlet flow, results in an increased area of separated flow. For a single airfoil, the flow is separated over $80 \%$ of the suction surface. At midspan, the separation extends up to the airfoil trailing edge. For supersonic flow conditions, low solidity results in an improvement in flow over the suction side because the bow shock moves in the downstream direction, and consequently the separation bubble caused by the bow shock impingement is reduced in size. For the isolated airfoil, the flow is attached over the entire suction surface.

- Local shocks over the suction surface of the high solidity cascade do not appear until a relatively high subsonic inlet flow Mach number of 0.95 . The shock structure for the range of inlet Mach numbers from 0.95 to 1.05 is very unstable and not periodic. Above a Mach number of 1.05 , the shock structure is stable and periodic. Generally, the shock structure consists of a lip (oblique) shock and a bow (termination) shock. It appears that the lip shock angle, once the shock is set, is independent of the inlet Mach number (at least for the range tested). The bow shock moves in the downstream direction as the inlet Mach number increases (that is, as the back pressure drops). Trailing edge shocks appear for inlet Mach numbers higher than 1.15. Similar observations were made also for the cases of low cascade solidity and a single airfoil.

- Computational results showed a good agreement with experimental results for the shock structure in the flow for the high solidity cascade, particularly on the upstream face of the cascade. The trailing edge shocks were not captured by the calculations. The prediction of flow separation for the supersonic inlet conditions agrees qualitatively with experiment. It appears that the separation bubble in the calculations starts closer to the leading edge than is seen in the experimental data. 


\section{REFERENCES}

[1] Carta, F.O.: Aeroelasticity and Unsteady Aerodynamics, Aircraft Propulsion System Technology and Design, edited by G.C. Oates, AIAA Education Series, Chapter 7, 1989.

[2] Boldman, D.R., Buggele, A.E., and Michalson, G.M.: Stall Flutter Experiment in a Transonic Oscillating Linear Cascade, NASA TM-82655, 1981

[3] Goldstein, M.E., Braun, W., and Adamczyk, J.J.: Unsteady Flow in a Supersonic Cascade with Strong In-passage Shocks, Journal of Fluid Mechanics, Vol. 83, pp. 569-604, 1977.

[4] Shaw, L.M., Boldman, D.R, and Buggele, A.E.: Unsteady Pressure Measurements on a Biconvex Airfoil in a Transonic Oscillating Cascade, NASA TM-86914, 1985.

[5] Buffum, D.H., Capece, V.R., King, A.J., and El-Aini, Y.M.: Oscillating Cascade Aerodynamics at Large Mean Incidence, NASA TM-107247, 1996.

[6] Lepicovsky, J., McFarland, E.R., Chima, R.V., and Wood, J.R.: On Flow Periodicity in the NASA transonic Flutter Cascade, Part I - Experimental Study, NASA TM-2000-209934, 2000.

[7] Chima, R.V., McFarland, E.R., Wood, J.R., and Lepicovsky, J.,: On Flow Periodicity in the NASA transonic Flutter Cascade, Part I - Numerical Study, NASA TM-2000-209933, 2000.

[8] Bradshaw, P.: Experimental Fluid Mechanics, Pergamon Press Ltd., 1970.

[9] Chima, R. V.: Explicit Multigrid Algorithm for Quasi-Three-Dimensional Viscous Flows in Turbomachinery, AIAA J. Propulsion and Power, Vol. 3, pp.397-405, 1987.

[10] Chima, R. V.: Calculation of Tip Clearance Effects in A Transonic Compressor Rotor, ASME Journal of Turbomachinery, Vol. 120, pp 131-140, 1998. 


\begin{tabular}{|c|c|c|c|c|}
\hline \multicolumn{3}{|c|}{ REPORT DOCUMENTATION PAGE } & & $\begin{array}{l}\text { Form Approved } \\
\text { OMB No. 0704-0188 }\end{array}$ \\
\hline \multicolumn{5}{|c|}{ 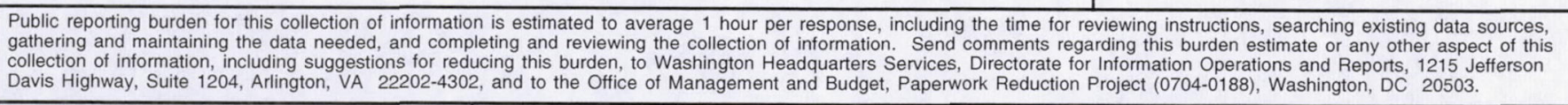 } \\
\hline 1. AGENCY USE ONLY (Leave blank) & \multicolumn{2}{|c|}{\begin{tabular}{|c|c|}
$\begin{array}{c}\text { 2. REPORT DATE } \\
\text { December } 2000\end{array}$ & 3. REPORT TYPE A
\end{tabular}} & \multicolumn{2}{|c|}{$\begin{array}{l}\text { NDD DATES COVERED } \\
\text { Technical Memorandum }\end{array}$} \\
\hline \multicolumn{3}{|c|}{$\begin{array}{l}\text { 4. TITLE AND SUBTITLE } \\
\text { Investigation of Flow Separation in a Transonic-Fan Linear } \\
\text { Cascade Using Visualization Methods }\end{array}$} & \multicolumn{2}{|c|}{ 5. FUNDING NUMBERS } \\
\hline \multicolumn{3}{|c|}{$\begin{array}{l}\text { Jan Lepicovsky, Rodrick V. Chima, Thomas A. Jett, Timothy J. Bencic, } \\
\text { and Kenneth E. Weiland }\end{array}$} & \multicolumn{2}{|c|}{ WU-523-26-13-00 } \\
\hline \multicolumn{3}{|c|}{$\begin{array}{l}\text { National Aeronautics and Space Administration } \\
\text { John H. Glenn Research Center at Lewis Field } \\
\text { Cleveland, Ohio } 44135-3191\end{array}$} & \multicolumn{2}{|c|}{ E-12488 } \\
\hline \multicolumn{3}{|c|}{$\begin{array}{l}\text { 9. SPONSORING/MONITORING AGENCY NAME(S) AND ADD } \\
\text { National Aeronautics and Space Administration } \\
\text { Washington, DC 20546-0001 }\end{array}$} & \multicolumn{2}{|c|}{$\begin{array}{l}\text { 10. SPONSORING/MONITORING } \\
\text { AGENCY REPORT NUMBER } \\
\text { NASA TM-2000-210521 }\end{array}$} \\
\hline \multicolumn{5}{|c|}{$\begin{array}{l}\text { 11. SUPPLEMENTARY NOTES } \\
\text { Prepared for the 9th International Symposium on Flow Visualization sponsored by the Heriot Watt University, Edinburgh, } \\
\text { Scotland, United Kingdom, August } 22-25,2000 \text {. Jan Lepicovsky, Dynacs Engineering Company, Inc., 2001 Aerospace } \\
\text { Parkway, Brook Park, Ohio } 44142 \text { (work funded by NASA Contract NAS3-98008); Rodrick V. Chima, Thomas A. Jett, } \\
\text { Timothy J. Bencic, and Kenneth E. Weiland, NASA Glenn Research Center. Responsible person, Jan Lepicovsky, } \\
\text { organization code 5810, 216-977-1402. }\end{array}$} \\
\hline \multirow{2}{*}{\multicolumn{3}{|c|}{ 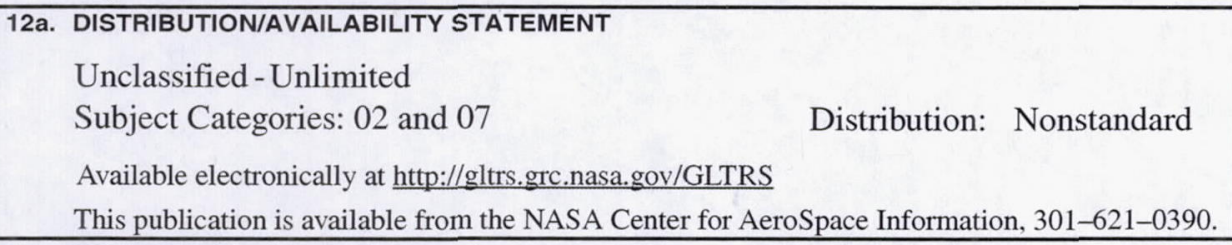 }} & \multirow{2}{*}{\multicolumn{2}{|c|}{ 12b. DISTRIBUTION CODE }} \\
\hline & & & & \\
\hline \multicolumn{5}{|c|}{$\begin{array}{l}\text { An extensive study into the nature of the separated flows on the suction side of modern transonic fan airfoils at high } \\
\text { incidence is described in the paper. Suction surface.flow separation is an important flow characteristic that may signifi- } \\
\text { cantly contribute to stall flutter in transonic fans. Flutter in axial turbomachines is a highly undesirable and dangerous } \\
\text { self-excited mode of blade oscillations that can result in high cycle fatigue blade failure. The study basically focused on } \\
\text { two visualization techniques: surface flow visualization using dye oils, and schlieren (and shadowgraph) flow visualiza- } \\
\text { tion. The following key observations were made during the study. For subsonic inlet flow, the flow on the suction side } \\
\text { of the blade is separated over a large portion of the blade, and the separated area increases with increasing inlet Mach } \\
\text { number. For the supersonic inlet flow condition, the flow is attached from the leading edge up to the point where a bow } \\
\text { shock from the upper neighboring blade hits the blade surface. Low cascade solidity, for the subsonic inlet flow, results } \\
\text { in an increased area of separated flow. For supersonic flow conditions, a low solidity results in an improvement in flow } \\
\text { over the suction surface. Finally, computational results modeling the transonic cascade flowfield illustrate our ability to } \\
\text { simulate these flows numerically. }\end{array}$} \\
\hline \multicolumn{3}{|l|}{ 14. SUBJECT TERMS } & & $\begin{array}{l}\text { 15. NUMBER OF PAGES } \\
19\end{array}$ \\
\hline \multicolumn{4}{|c|}{ Transonic airfoil; Flow separation; Surface flow visualization; Shock wave structure } & $\begin{array}{l}\text { 16. PRICE CODE } \\
\text { A03 }\end{array}$ \\
\hline $\begin{array}{l}\text { 17. SECURITY CLASSIFICATION } \\
\text { OF REPORT } \\
\text { Unclassified }\end{array}$ & $\begin{array}{l}\text { 18. SECURITY CLASSIFICATION } \\
\text { OF THIS PAGE } \\
\text { Unclassified }\end{array}$ & $\begin{array}{l}\text { 19. SECURITY CLASSIFIC } \\
\text { OF ABSTRACT } \\
\text { Unclassified }\end{array}$ & & 20. LIMITATION OF ABSTRACT \\
\hline
\end{tabular}

